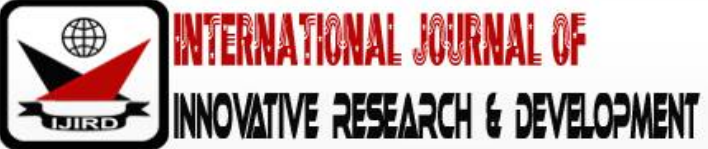

ISSN 2278 - 0211 (Online)

\section{Demographic Factors Accounting for Variations in Tutors' Perceptions of the Transformational Leadership Practices of Their College Principals: A Study of the Colleges of Education in Ghana}

\author{
Dr. Robert Afayori \\ Alumni, Newcastle University, UK
}

\begin{abstract}
:
Many empirical research studies on school leadership consistently demonstrate the impact of principals' transformational leadership practices on teachers' performance, teachers' commitment and job satisfaction. While most of these studies identify the specific leadership practices that contribute significantly to these teacher-effect variables, what is less studied and very much less researched is the extent to which teacher demographic factors such as age, race, gender, socio-economic status, academic qualification, and years of experience impact on variations of their perceptions of leadership. This current study investigates the extent to which some of these demographic factors impact on tutors' perceptions of their principals' transformational leadership in the University Colleges of Education in Ghana. The study involved responses from 434 tutors. Data was sourced through the use of the Principal Leadership Questionnaire (PLQ). Data was analysed using descriptive and inferential statistics such as means and standard deviations, $t$-test, and ANOVA. Findings indicated that tutors perceived the leadership practices of their principals to be transformational. Transformational leadership practice such as: providing vision, modelling best behaviour, fostering commitment and holding high performance expectations recorded higher mean scores while leadership practices such providing individual support and intellectual stimulation showed lower scores. There was no statistically significant relationships between the studied demographic factors and tutors' perceptions of leadership. This finding had significant implications for leadership practices in the studied colleges.
\end{abstract}

Keywords: Principal leadership, transformational leadership, tutor perceptions, tutor demographics

\section{Introduction}

Many research studies have consistently shown that principal leadership is the catalyst to school effectiveness and improvements (Leithwood and Jantzi, 1999; Hallinger, 2003; Marks and Printy, 2003; Leithwood et al., 2006; Robinson et al., 2008; Hallinger and Heck, 2012; Shatzer et al., 2014; Day et al., 2016). While student progress and academic achievements are often seen as the measurable outcomes of successful principal leadership (Robinson et al., 2008; Shatzer et al., 2014; Day et al., 2016), empirical studies in the area demonstrate that principal leadership practices only directly impact on the school culture and organisation as well as teacher attitude and instructional practices (Marks and Printy, 2003; Hallinger, 2003; Leithwood et al., 2006; Hallinger, 2010; Le Fevre et al., 2015; Day et al., 2016). For instance, results from Hallinger's (2010) review of 30 years of empirical research on the effects of school leadership shows that principal leadership has indirect or mediated effects on student learning and academic achievements. The study shows that principal leadership directly impacted on school climate and teacher attitude and performance.

Among all the leadership models related to principal leadership of schools (such as managerial, transactional, instructional, transformational, distributed, moral, participative, emotional, contingent, and postmodern), the leadership models that are often associated to student learning and teacher-effect variables are instructional and transformational leadership. In the analytical variations of the effects of transformational and instructional leadership, whereas instructional leadership directly impacts on student progress and academic achievements, transformational leadership directly impacts on teacher-effect variables and school conditions that make student learning possible (Dankwa, 2013; Shatzer et al., 2014; Day et al., 2016).While transformational leadership emphasises 'on vision and inspiration, setting directions, developing people, (re)designing the organisation, and establishing structures and cultures that enhance the quality of teaching and learning (Day et al., 2016: 224), empirical research show that this model of leadership impacts on school culture and climate, teacher attitude and performance, teacher commitment and job satisfaction (Jantzi and Leithwood, 1996; Blaise and Blaise, 1999; Bredeson, 2000; Ross and Gray, 2006; Bell and Bolam, 2010; Rhodes and Brundrett, 2010; Hauserman and Stick, 2013).

If leadership is simply defined as 'a social influence process' (Yukl, 1989; 2002)in which people perceive others as possessing certain leadership qualities for which they consent to be led (Jantzi and Leithwood, 1996: 530), then the way 
teachers perceive their principals' transformational leadership practices is as crucial to their leadership effectiveness as it is with the type of leadership practices principals exercise in schools. It is often said that perceptions define the meanings and interpretations people give to reality (Flad, 1989; Williams, 2006; Helms, 2012). Yet, there are factors such as age, race, gender, socio-economic status, academic qualifications and years of experience among others which contribute to shaping the perceptions people form about perceived reality. While many research studies have investigated the extent to which principal leadership impact on school improvements and effectiveness (Hallinger, 2003; Robinson et al., 2008; Shatzer et al., 2014; Day et al., 2016), very little is known about the extent to which teacher demographic factors impact on their perceptions of the transformational leadership practices of their college principals. This study investigates this relationship in the University Colleges of Education in Ghana.

\section{Literature Review}

The literature review under this section focuses on the meaning and development of transformational leadership, its effects on schools, teacher performance, and the extent to which demographic factors influence teachers' perceptions of this form of leadership. The purpose is to understand the conceptual underpinnings of transformational leadership and explore literature on the relationship between teachers' demographic factors and their perceptions of this model of leadership. As indicated, if leadership is considered as a 'social influence process' whereby a leader inspires the actions of followers to achieve intentional outcomes (Yukl, 2002: 3; Bush, 2012: 6), then it is significant to understand the extent to which demographic factors impact on the meaning and interpretations followers give to the actions and behaviours of their leaders. It is for this reason that this section explores literature on the above variables.

\subsection{Understanding Transformational Leadership}

The assumption of transformational leadership indicates that when the central focus of leadership is directed to the commitment and capacities of organisational members, it produces higher levels of personal commitment to organisational goals and greater capacity to accomplishing these goals (Leithwood et al., 1999; Leithwood and Sun, 2012). This reflects the conception that when members of an organisation are given the requisite support, they become highly engaged and motivated by organisational goals which are associated with certain values to which they strongly share (Leithwood and Sun, 2012: 388). In this way, what transformational leaders need to do is to identify the internal states of members which are critical to their performance and direct the kind of leadership strategies that are likely to positively influence them in response to organisational goals (Leithwood and Sun, 2012: 389). Thus, development of members as an effective means to accomplishing organisational goals is the central focus of transformational leadership.

The concept was first developed by McGregor Burns in 1978 to describe the ideal relations between leaders and followers in an organisation. He described 'transforming leadership' as leaders' ability to persuade followers to act in response to certain goals that represent the values, needs and motivations of both leader and followers. Thus, Burns (1978) conceived a distinct difference between transforming leadership and transactional leadership. Whereas transactional leadership appeals to an individual's interest on the basis of an exchange process (on a give-and-take basis), transforming leadership appeals to a long-term higher level of work performance. Bass (1985) however developed and extended Burns' (1978) model by positing that leadership is constituted by three domains: (i) transformational; (ii) transactional; (ii) and laissez-faire forms of leadership. He was the first to use the term 'transformational leadership'. Unlike Buns (1978), Bass (1985) indicated that while transactional leadership traits (for example, salary recognition or offering contingent rewards) is good for maintaining the organisation and ensuring that normal courses of action operate smoothly, transformational leadership appeals to the shared goals and interest of both followers and leaders in the organisation. Hence, the two are not dichotomous but dimensions of leadership that can be found in the same person in greater or lesser degree. Bass (1985)therefore conceived a two-factor model of leadership where transformational and transactional leadership form a continuum. To measure this form of leadership traits, Bass and Avolio (1994) developed the Multifactor Leadership Questionnaire (MLQ) to measure the two-factor model of leadership. The instrument has two forms: the follower's rater (Form 5X) and self-rater (Form 6S). The MLQ (Form 5X) measures the following leadership factors: (1) idealized influence; (2) inspirational motivation; (3) intellectual stimulation; (4) individual consideration; (5) contingent Rewards;(6) management-by-exception; and (7) laissez-Faire leadership. The MLQ was used to measure leadership practices in different organisations and institutions.

However, transformational leadership was introduced into schools by Leithwood and colleagues (1992; 1994; 1999). They extended Burns' (1978) and Bass' (1985) models to include other leadership characteristics such as: building school vision and establishing school goals; providing intellectual stimulation; offering individualized support; modelling best practices and important organizational values; demonstrating high performance expectations; creating a productive school culture; and developing structures to foster participation in school decision-making (Leithwood, 1994; Leithwood et al., 1999; Leithwood and Sun, 2012: 399-401).Leithwood and Sun (2012) grouped these attributes of transformational leadership into three major categories such as: (i) setting directions (develop shared vision and foster goal consensus; and hold high performance expectations); (ii) develops people (provides individualised support, provides intellectual stimulation and models best practice and important organisational values); (iii) and redesigning the organisation (creating a productive school culture and building structures to enable collaboration). Leithwood and colleagues (1994; 1996) developed instruments such as: The Nature of School Leadership Scale (NSLS) and the Principal Leadership Questionnaire (PLQ) for measuring these leadership factors.

For instance, in their series of three studies on transformational leadership, Leithwood and colleagues (1992) found that school leaders who practiced transformational leadership continuously pursued three fundamental goals: (i) they helped teachers develop and maintain professional school culture; (ii) fostered teacher professional development; 
(iii) and supported teacher collaborative efforts at effectively solving problems (Leithwood, 1992: 69-70). In the many studies on the effects of transformational leadership on schools and teachers, the development and maintenance of effective school culture, the fostering of teacher professional development and the promotion of teacher collaboration in the implementation of reforms are seen as gold standard means of ensuring school effectiveness and improvements (Marks and Printy, 2003; Hallinger, 2003; Leithwood and Jantzi, 2012; Shatzer et al., 2014; Day et al., 2016). Thus, it could be said that transformational leadership focuses on setting directions, improving the organisation and its members in order to achieve organisational goals.

While the success of principals' transformational leadership practices are dependent on their effects on schools and teachers, the extent to which teachers perceive their principals to be exercising this leadership model is also a determinant factor. As Jantzi and Leithwood (1996) put it, 'doing good work on behalf of one's school, and being seen to do such work, is likely to be the most powerful strategy for positively influencing teachers' perceptions of one's leadership' (p.531). Consequently, while teachers' perceptions of their principals' transformational leadership depend on the extent to which teachers identify transformational leadership qualities in their principals,it is said that perceptions are also shaped by demographic factors such as age, race, gender, education, experience and socioeconomic status. This review explores literature on the relationship between teacher demographic factors and their perceptions of leadership. Do these factors impact on variations of teachers' perceptions of their principals' transformational leadership?

\subsection{Demographic Factors and Perceptions of Transformational Leadership}

Teachers' perceptions of the transformational leadership practices of their principals often bother on the meanings and interpretations teachers give to the leadership practices of these principals. It concerns the way teachers view the actions undertaken by their principals in response to school goals (Flad, 1989; Williams, 2006; Helms, 2012). While the concept 'perception' is often criticised by rationalist researchers as an inferior source of knowledge because of the element of subjectivity associated to it (see, Flad, 1989: 45; Lee et al., 1993: 157), perceptions nonetheless represent people's views about a subject matter. These views very often influence their actions. This explains why perceived reality is important because it influences the actions of perceivers and evoke certain responses from them (Andrew, 1987: cited in Flad, 1989). As Flad (1989) indicated, 'one's perceptions of his surroundings provide a powerful influence on how he acts and views his environment' (p.46). In this way, 'when teachers have a positive perception of the quality of their workplace and the support of their principals, they are more productive, more efficient, and feel better about the job they are able to do for students' (Flad, 1989:45-6).

While perceptions are subjective in character, examining teachers' perceptions of their principals' leadership practices may also imply the examination of the relative differences in their perceptions as a result of the different meanings and interpretations each teacher might give to their principals' leadership behaviours. Yet, such differencesmay also be the result of certain teacher demographic factors such as age, gender, race, qualification and experience and socioeconomic status among others. For instance, Lee and colleagues (1993) identified gender as a significant factor that accounts for the within school variations of teachers' perceptions of leadership (p.154). Their study explored the effects of teachers' and principals' gender on perceptions of principals' leadership, and how these perceptions also influence their organisational, interpersonal and personal domains. As a descriptive survey, data was drawn from 8,894 high school teachers from about 300 high schools.

Results of Lee and colleagues' (1993) study indicated the following: (1) In terms of effective leadership, while male and female teachers assessed the transformational leadership practices of their principals to be equally effective, there were large statistically significant differences in their perceptions of female principals. Male teachers perceived their female principals as ineffective while female teachers considered the same principals to be effective; (2) In respect of selfefficacy, both male and female teachers who worked with female principals experienced exceptional personal power in contrast to those who worked with male principals; (3) with interpersonal power or collegiality, women teachers' interpersonal power was considerably greater than men teachers regardless of the gender of the principals. However, male teachers felt their interpersonal power was curtailed with working with female principals (Lee et al., 1993:168).These findings led Lee and colleagues (1993) to conclude that while there are differences in male and female teachers' perception of leadership practices, such differences are even more stark when the gender of the principal is concerned.

In contract, Jantzi and Leithwood (1996) also conducted a study on teachers' perceptions of the transformational leadership practices of their principals. Their study focused on the extent to which alterable and unalterable variables contributed to variations in teachers' perceptions of their principals' transformational leadership. The alterable variables included: (1) in-school conditions (school mission and goals, culture, structure, program and instructions, policies and resources); and (2) out-of-school condition (school district, the ministry of education and the local school community). The unalterable conditions included: (1) the demographic characteristics of teachers and principals such as gender, age and length of experience; and (2) school characteristics such as school level (elementary, middle and secondary schools) and school size (Jantzi and Leithwood, 1996: 519).While the study was descriptive in nature, it was conducted in elementary and secondary schools in British Columbia involving 423 teachers. The study was a survey conducted in two phases of a 5year longitudinal study. Results of their analyses indicated that while in-school conditions accounted for the most variations in teachers' perceptions of their principals' leadership, demographic factors such as gender, age and experienced did not statistically account for the variations in teachers' perceptions of leadership.

Biggerstaff (2012) also conducted a study involving 179 elementary school teachers from Kentucky in North America. The study focused on the relationship between teachers' perceptions of their principals' transformational leadership and how these impact on their job satisfaction. It also examined the extent to which different demographic 
factors such as age, experience and education influenced variations in teachers' perceptions of their principals' transformational leadership. Teachers' age was categorised as: (21-30); (31-40) and (41+) with their years of experience as: group one (0-4); group two (5 to 11); group three (12-19) and group four (20+). Teachers' levels of education were also categorised as: Bachelors; Masters and Rank 1.The results of the ANOVA indicated the following: (1) in respect of teachers' age, younger teachers (21-30) rated their principals' transformational leadership significantly higher than older teachers (31-40); (2) in terms of academic levels, younger teachers with bachelors rated their principals' leadership higher than teachers with Rank 1; (3) however, there was a lack of statistically significant difference between the various years of experience and teachers' perceptions of leadership (Biggerstaff, 2012: 95-96).

Contrastingly, Helm (2012) also conducted a quantitative study which compared the relationship between principals' perceptions of their leadership behaviours and their teachers' perceptions of their leadership. The study involved 259 teachers and 8 principals from elementary and secondary schools from North Carolina (USA). While the study used Kouzes and Posner's (2003) Leadership Practices Inventory (LPI) for self (principals) and observer's(teachers) assessments of their perceptions, it specifically examined the impact of demographic factors such as: (1) gender; (2) years of experience; and (3) whether they were hired by their current principals, on teacher perceptions of transformational leadership. Results indicated that there were little discrepancies in the overall scores between teachers and principals' perceptions of leadership. However, secondary school teachers rated their principals' leadership behaviours as more observed than the principals themselves (Helm, 2012: 81-82).

In terms of the extent to which demographic factors accounted for variation in teachers' perceptions of leadership, the following was found: (1) gender did not have significant effect on teachers' perceptions of principals' transformational leadership; (2) teachers' years of experience (which ranged 0-10; 11-15; 16-20; 21-25; and more than 25 years) showed significant differences between teachers with (11-15) and those with (more than 25) years of experience; (3) whether or not current principals hired the teachers did not impact on variations of teachers' perceptions of leadership (Helm, 2012: 121).The study also found that older principals displayed less exemplary leadership behaviours than their younger counterparts. In this way, Helm (2012) recommended that younger principals should be selected to lead schools since they exhibit strong exemplary leadership qualities (Helm, 2012: 129).

Walker and Slear's (2011) study also examined the relationship between teachers' self-efficacy beliefs and their perceptions of leadership. The study involved 366 middle school teachers' in Mid-Atalanta, USA. Although the study focused on the impact of leadership on teachers' self-efficacy, it nonetheless examined the influence of teachers' years of experience on variations of their perceptions of transformational leadership. Teachers' years of experience were categorised under the following: 0-3 (new teachers); 4-7 (experienced teachers); 8-14 (very experienced) and 15+ (extensively experienced teachers). Principals' leadership practices were measured using their self-formulated Principals' Behaviour Survey. While stepwise linear regression was used for data analysis, findings on the relationship between teachers' experience and perceptions indicated that the more teachers gained experience in their teaching career, the less they depended on their principals' leadership practices to be effective. As experts in their field, experienced teachers perceived their principals' leadership practices to be less relevant to them. However, novice teachers depended more on their principals' leadership practices.

In consequence, one discovers that findings of the above reviewed studies demonstrate in varying degrees that teacher demographic factor influence their perceptions of leadership. While some studies found that demographic factors such as gender, academic qualification and years of experience influenced teachers' perceptions of their principals' leadership (Lee et al., 1993; Walker and Slear, 2011; Biggerstaff, 2012), others found no statistically significant relationship between these factors and perceptions of leadership (Jantzi and Leithwood, 1996; Helm, 2012). What is however observed in the reviewed studies is the lack of studies on the relationship between demographic factors and teachers' perceptions of leadership in tertiary institutions. It is in response to this lack of literature in the area that this current study investigates the relationships between these two variables in the University Colleges of Education in Ghana.

\section{Research Questions}

- The study is therefore guided by the following research questions and hypothesis:

- To what extent do tutors of the University Colleges of Education in Ghana perceive the leadership practices of their college principals to be transformational?

- To what extent do demographic factors such as gender, qualification and experience account for variations in tutors' perceptions of the leadership practices of their college principals?

Null Hypothesis: Gender, qualification and experience do not account for variations in tutors' perceptions of their principals' leadership practices in the colleges of education in Ghana.

\section{Research Methodology}

\subsection{Research Design and Methods}

The current study is a descriptive survey. Cohen and colleagues (2016) assert that descriptive surveys 'set out to describe, compare, contrast, classify and interpret entities and events that constitute their various fields of inquiry' (p.257). According to Best and Kahn (1995; cited in Dankwa, 2014:189), such surveys also deal with determining the nature of prevailing conditions, practices, attitudes, perceptions and opinions that are held, processes that are on-going or trends that are developed. While descriptive surveys simply describe data on variables of interest, Cohen and colleagues (2016) further indicated that analytic surveys 'operate with hypothesised predictors or explanatory variables that are 
tested for their influence on dependent variables' (p.257). These tests are conducted to ascertain the extent to which the independent variable accounts for variations in the dependent.

Thus, this current study embraced the two approaches above, in that, it analyses and describes the extent to which tutor demographic factors such as gender, qualification and experience accounted for variations in tutor perceptions of the transformational leadership practices of their college principals. As was demonstrated in the literature review, studies show that there are statistically significant relationships between these factors and tutors' perceptions of their principals' transformational leadership practices. This study therefore seeks to ascertain and describe the extent to which tutors consider their principals' leadership practices to be transformational, and whether or not demographics factors account for variations in their perceptions of leadership.

To achieve this end, the study used standardised questionnaires for data collection on tutors' perceptions of their principals' transformational leadership practices. Here, Jantzi and Leithwood's (1996) Principals Leadership Questionnaire (PLQ) were used for garnering data on tutors' perceptions of their principals' leadership practices. The PLQ contained 24 questionnaire items designed on 6 principals' leadership practices such as: provides vision (PV), fosters commitment (FC), provides individual support (IS), provides intellectual stimulation (NS), models behaviour (MB), and holds high performance expectation (HE); with a 4-point Likert scale ranging from StronglyDisagree (1) to StronglyAgree (4).

\subsection{Research Population and Instrumentation}

A representative sample was selected for data collection and analysis. Denscombe (2014) indicates that 'a representative sample involves a cross-section of the population. It matches the population in terms of its mix of ingredients [by] using a selection procedure that: (1) includes all relevant factors; (2) matches the proportions in the overall population' (p.32). To ensure that the sample was representative and generalizable, the study used probability sampling methods, focusing specifically on cluster sampling methods and. Cluster sampling is normally useful when the population is large and widely dispersed (Cohen et al., 2016).

Thus, 15 University Colleges from 4 regions in Ghana were selected using cluster sampling procedures. An estimated representative sample size of 629 tutors from 15 selected colleges in the four regions was anticipated for the study.Paper-pencil questionnaire were personally distributed by the researcher to the 629 tutors from the 15 colleges of education in the 4 selected regions/clusters. 444 completed responses were returned representing a response rate of $70.5 \%$. However, 10 responses were rejected due to incomplete responses to some items in the questionnaire.

\section{Data Analysis and Findings}

For the purposes of the analysis of data, raw data consisting of item-by-item responses by tutors in the PLQ instruments was first entered into Excel spreadsheet and then exported to SPSS version MAC 24 to establish descriptive and inferential statistics. SPSS was used to analyse survey response in order to establish the reliability of the instrument. According to Gall and colleagues (2003), reliability measures of 0.70 or higher are sufficient for research purposes. While the reliability of the PLQ as found by Jantzi and Leithwood (1996) ranged from 0.73 to 0.91 , this study found values ranging between 0.75 to 0.87 . These were deemed to be tenable for the study. Descriptive statistics were generated and organised according to survey instrument, survey constructs and for each college. Univariate and bivariate analyses were conducted to establish descriptive and inferential statistics.

Various analyses were conducted in response to the following: (a) ascertaining tutors' perceptions on whether or not their principals' leadership practices are transformational; (b) determining the statistically significant differences between male and female tutors' perceptions of leadership; (c) establishing whether or not tutors' experience; and (d) years of work with their current principals, accounted for any statistically significant differences in their perceptions of leadership. In this way, while tutors' perceptions were measured using descriptive statistics (mean scores and standard deviations) following the six factors of transformational leadership, independent sample test ( $t$-test) was used to determine the statistically significant difference between male and female tutors' perceptions of leadership. Analysis of Variance (ANOVA) was used to determine the statistically significant differences in tutors' perceptions following their experience and years of work with current principals.

\subsection{Research Question One}

To what extent do tutors in the colleges of education in Ghana perceive the leadership practices of their principals to be transformational?

Tutors' perceptions were measured against the backdrop of the following six factors of the PLQ: provides vision (PV), models behaviour (MB), foster commitment (FC), provides individual support (ISL), provides intellectual stimulation (NS) and holds high performance expectations (HE). Following the 4-point Likert scale, the higher the ratings, the more tutors considered their principals' leadership practices to be transformational. Table 1 shows the results of the analysis. The overall average score of tutors' perceptions of leadership was ( $M=3.02, S D=0.57)$ indicating that tutors agreed that their principals' leadership practices were transformational. 


\begin{tabular}{|c|c|c|c|c|cc|}
\hline Factors & $\mathbf{N}$ & Minimum & Maximum & Mean & \multicolumn{2}{|c|}{ Std. Deviation Reliability } \\
\hline PLQ & & & & $\mathbf{3 . 0 2}$ & \multicolumn{2}{|c|}{$\mathbf{0 . 5 7}$} \\
PV & 434 & 1.00 & 4.00 & 3.03 & 0.59 & $\mathbf{0 . 8 6}$ \\
\hline MB & 434 & 1.00 & 4.00 & 3.05 & 0.64 & $\mathbf{0 . 8 5}$ \\
\hline FC & 434 & 1.00 & 4.00 & 3.05 & 0.57 & $\mathbf{0 . 8 7}$ \\
\hline ISL & 434 & 1.00 & 4.00 & 2.87 & 0.57 & $\mathbf{0 . 8 3}$ \\
\hline NS & 434 & 1.00 & 4.00 & 2.92 & 0.57 & $\mathbf{0 . 7 7}$ \\
\hline HE & 434 & 1.00 & 4.00 & 3.24 & 0.52 & $\mathbf{0 . 7 5}$ \\
\hline Valid N & 434 & & & & & \\
(listwise) & & & & & & \\
\hline
\end{tabular}

Table 1: Tutors' Perceptions of Their Principals' Transformational Leadership Practices.

$P V=$ Provides Vision, $M B=$ Models Behaviour, FC = Fosters Commitment, ISL = Individual Support, NS = Intellectual Stimulation, $H E=$ High Performance Expectations.

As table 1 shows, apart from the fact that leadership practices such as providing individual support (ISL) and intellectual stimulation (NS) recorded the lowest mean scores, the mean scores of the rest of the factors demonstrated that tutors of the studied colleges of education in Ghana agreed that their principals' exercise transformational leadership practices such as: provides vision, models behaviour, foster commitment and holds high performance expectations.

\subsection{Research Question Two}

To what extent do demographic factors such as gender, qualification and experience account for variations in tutors' perceptions of the leadership practices of their principals in the colleges of education in Ghana?

Ho1: Gender, qualification and years of experience do not account for variations in tutors' perceptions of their principals' transformational leadership practices in the colleges of education in Ghana.

Under this second research question, three research sub-questions and hypotheses were developed to determine: (a) the statistical difference between male and female tutors' perceptions of leadership; (b) establish whether or not tutors' experience; and (c) years of work with their current principals account for any statistically significant differences in their perceptions of leadership. These sub-questions and analyses are presented below:

\subsubsection{Research sub-question $2 \mathrm{a}$}

Is there a statistically significant difference between male and female tutors' perceptions of their Principals' transformational leadership practices?

Ho1: There is no statistically significant difference between male and female tutors' perceptions of their principals' transformational leadership practices.

The overall mean scores of male and female tutors' perceptions of their principals' transformational leadership practices are presented in table 2 . To evaluate the null hypothesis, an independent sample test ( $t$-test) was conducted based on the understanding that the two groups were unrelated. Following Levene's test for the equality of variance, the row on 'equal variance assumed' was used because the $p$-value of the Levene's test proved to be statistically nonsignificant $(p=0.43)$

\begin{tabular}{|c|c|c|c|c|c|}
\hline \multicolumn{2}{|c|}{ Factors Gender } & $\mathbf{N}$ & Mean & Std. Deviation & Std. Error Mean \\
\hline \multirow{2}{*}{ PV } & Male & 318 & 3.04 & 0.62 & 0.03 \\
\cline { 2 - 6 } & Female & 116 & 3.04 & 0.56 & 0.05 \\
\hline \multirow{2}{*}{ MB } & Male & 318 & 3.06 & 0.67 & 0.04 \\
\cline { 2 - 6 } & Female & 116 & 3.06 & 0.55 & 0.05 \\
\hline \multirow{2}{*}{ FC } & Male & 318 & 3.05 & 0.59 & 0.03 \\
\cline { 2 - 6 } & Female & 116 & 3.06 & 0.51 & 0.05 \\
\hline \multirow{2}{*}{ ISL } & Male & 318 & 2.87 & 0.59 & 0.03 \\
\cline { 2 - 6 } & Female & 116 & 2.88 & 0.53 & 0.03 \\
\hline \multirow{2}{*}{ NS } & Male & 318 & 2.94 & 0.57 & 0.05 \\
\cline { 2 - 6 } & Female & 116 & 2.90 & 0.58 & 0.03 \\
\hline \multirow{2}{*}{ HE } & Male & 318 & 3.24 & 0.53 & 0.05 \\
\cline { 2 - 6 } & Female & 116 & 3.24 & 0.49 & \\
\hline
\end{tabular}

Table 2: Mean Scores of Male and Female Tutors' Perceptions of Leadership.

$P V=$ Provides Vision, $M B=$ Models Behaviour, FC = Fosters Commitment, ISL = Individual Support, NS = Intellectual Stimulation, $H E=$ High Performance Expectations. 


\begin{tabular}{|c|c|c|c|c|c|c|}
\hline \multicolumn{2}{|c|}{} & \multicolumn{2}{|c|}{$\begin{array}{c}\text { Levene's Test } \\
\text { for Equality of } \\
\text { Variances }\end{array}$} & \multicolumn{3}{c|}{ t-test for Equality of Means } \\
\cline { 3 - 7 } & & $\mathrm{F}$ & Sig. & $\mathrm{t}$ & $\mathrm{df}$ & Sig. (2-tailed) \\
\hline \multirow{2}{*}{ PV } & Equal variances assumed & 3.359 & .068 & .021 & 432 & .983 \\
\cline { 2 - 7 } & Equal variances not assumed & & & .022 & 224.033 & .982 \\
\hline \multirow{2}{*}{ MB } & Equal variances assumed & 8.913 & .003 & -.068 & 432 & .945 \\
\cline { 2 - 7 } & Equal variances not assumed & & & -.075 & 249.207 & .940 \\
\hline \multirow{2}{*}{ FC } & Equal variances assumed & 4.314 & .038 & -.360 & 432 & .719 \\
\cline { 2 - 7 } & Equal variances not assumed & & & -.387 & 237.207 & .699 \\
\hline \multirow{2}{*}{ ISL } & Equal variances assumed & 1.498 & .222 & -.217 & 432 & .828 \\
\cline { 2 - 7 } & Equal variances not assumed & & & -.229 & 228.361 & .819 \\
\hline \multirow{2}{*}{ NS } & Equal variances assumed & .284 & .594 & .553 & 432 & .580 \\
\cline { 2 - 7 } & Equal variances not assumed & & & .549 & 201.688 & .583 \\
\hline \multirow{2}{*}{ HE } & Equal variances assumed & .133 & .716 & -.037 & 432 & .970 \\
\cline { 2 - 7 } & Equal variances not assumed & & & -.038 & 217.237 & .969 \\
\hline
\end{tabular}

Table 3: Independent Samples Test of Gender and Tutors' Perceptions of Leadership

$P v=$ Provides Vision, $M b=$ Models Behaviour, Fc = Fosters Commitment Isl = Individual Support, Ns = Intellectual Stimulation, He = High Performance Expectations .

The results of the independent sample $t$-test as shown in table 3 demonstrates the lack of statistically significant differences between male and female tutor perceptions of their principals' transformational leadership following the six leadership practices. In this way, the null hypothesis (Ho1) was supported in the analysis. Since these tutors assessed their principals' leadership practices to be transformational, the confirmation of the null hypothesis implies that male and female tutors in the studied colleges of education in Ghana exhibited shared (or similar) perceptions that their principals exercised transformational leadership practices such as: provide vision, model best behaviour, fosters commitment, provides individual support, provides intellectual stimulation and holds higher performance expectations. As Cohen and colleagues (2016) intimated, the demonstration of shared perceptions between male and female tutors imply that the implementation of such leadership strategies is likely to produce similar effects on tutors (p.643).

\subsubsection{Research Sub-question $2 \mathrm{~b}$}

To what extent do tutors' 'qualifications' account for the variances in their perceptions of principals' transformational leadership practices?

Ho5: There are no statistically significant differences in tutors' perceptions of their principals' transformational leadership following their qualifications.

In response to this research sub-question, one-way analysis of variance (ANOVA) was used to determine whether or not there are statistically significant differences between the four mean scores of tutors' academic qualifications (diploma, first degree, masters and PhD) where $\alpha=0.050$. The Tukey test will then be used to identify the exact locus of the differences (Cohen and colleagues, 2016: 646).

\begin{tabular}{|c|c|c|c|c|}
\hline Qualifications & $\mathbf{N}$ & Mean & Std. Deviation & Std. Error \\
\hline Diploma & 3 & 3.51 & 0.25 & 0.14 \\
\hline First degree & 29 & 2.91 & 0.58 & 0.10 \\
\hline Masters & 399 & 3.01 & 0.51 & 0.02 \\
\hline PhD & 3 & 2.88 & 0.38 & 0.22 \\
\hline Total & 434 & 3.01 & 0.52 & 0.02 \\
\hline
\end{tabular}

Table4: Mean Scores of Tutors' Perceptions of Leadership Following Their Academic Qualifications

\begin{tabular}{|c|c|c|c|c|c|}
\hline & Sum of Squares & df & Mean Square & F & Sig. \\
\hline Between Groups & 1.093 & 3 & .364 & 1.345 & .259 \\
\hline Within Groups & 116.431 & 430 & .271 & & \\
\hline Total & 117.524 & 433 & & & \\
\hline
\end{tabular}

Table 5: ANOVA of Tutors' Perceptions of Leadership Following Their Academic Qualification

The mean scores of tutors following their academic qualifications are displayed in table 4. These were measured following their general assessments of the transformational leadership practices of their principals. The assumption of normality was evaluated and found tenable for all categories of academic qualification. The assumption of homogeneity of variance was also evaluated and found acceptable using Levene's Test, $F(3,430)=0.775, p=0.508$. The analysis of variance (ANOVA) was found to be statistically no significant $F(3,430)=1.345, p=0.259$. Thus, the null hypothesis (Ho2) was confirmed. The lack of statistically significant differences of between groups also implied a lack of statistically significant pair wise difference of among groups in the post hoc test. In this way, the analysis showed that tutors' academic 
qualifications did not account for variation in their perceptions of the transformational leadership practices of their principals.

\subsubsection{Research Sub-question 2c}

To what extent do tutors' 'years of work as tutors' account for the variances in their perceptions of principals' transformational leadership practices?

Ho5: There are no statistically significant differences in tutors' perceptions of their principals' transformational leadership following tutors' 'years of work as tutors'.

Tutors 'years of experience ranged from: (1 to 5); (6 to 10); (11 to 15); (16 to 20); (21 to 25); (26 to 30); and (31 to 35). Tutors' mean scores following their years of experience is shown in table 6. The analysis of variance (ANOVA) was conducted to determine the extent to which tutors' years of experience may accounted for statistically significant differences in their perceptions of the transformational leadership practices of their principals in general.

\begin{tabular}{|c|c|c|c|c|}
\hline Years of Experience & $\mathbf{N}$ & Mean & Std. Deviation & Std. Error \\
\hline $0-5$ & 147 & 3.11 & 0.52 & 0.04 \\
\hline $6-10$ & 132 & 2.96 & 0.49 & 0.04 \\
\hline $11-15$ & 92 & 2.92 & 0.56 & 0.05 \\
\hline $16-20$ & 40 & 2.99 & 0.47 & 0.07 \\
\hline $21-25$ & 11 & 2.90 & 0.51 & 0.15 \\
\hline $26-30$ & 7 & 2.98 & 0.29 & 0.10 \\
\hline $31-35$ & 5 & 3.00 & 0.32 & 0.14 \\
\hline Total & 434 & 3.00 & 0.52 & 0.02 \\
\hline
\end{tabular}

Table 6: Mean Scores of Tutors' Years of Experience and Perceptions of Leadership

\begin{tabular}{|c|c|c|c|c|c|}
\hline & Sum of Squares & df & Mean Square & F & Sig. \\
\hline Between Groups & 2.785 & 6 & .464 & 1.728 & .113 \\
\hline Within Groups & 114.739 & 427 & .269 & & \\
\hline Total & 117.524 & 433 & & & \\
\hline
\end{tabular}

Table 7: ANOVA of Tutors' Years of Experience and Perceptions of Leadership

The assumption of homogeneity of variance was evaluated and found tenable using Levene's Test, $F(6,427)=$ $1.034, p=0.402$. The analysis of variance (ANOVA) was not found to be statistically significant $F(6,427)=1.728, p=$ 0.113.Thus, the null hypothesis (Ho5) was supported ( $p>0.05)$. This implied that the differences in tutors' 'years of experience did not account for any statistically significant differences in their perceptions of the transformational leadership practices of their college principals.

\section{Discussion of Research Findings}

Understanding tutors' perceptions of their principals' leadership practices is particularly important because these views offer feedback to principals on what tutors make of their leadership behaviours and their potential impact on their performance. As Jantzi and Leithwood (1996) noted, 'knowledge generated by such a focus will be of direct use in improving school leader effects' (p.512). As shown in the descriptive results, tutors of the studied colleges of education in Ghana generally perceived that their principals' leadership practices were transformational. This is demonstrated by theoverall average mean score of $(M=3.02, S D=0.57)$. This was consistent with the results of Dankwa's (2013) earlier study which examined tutors' views on the leadership practices of their principals in similar colleges of education in Ghana.

While tutors viewed their principals to strongly exercise transformational leadership practices such as provides vision, models best behaviour, fosters commitment and holds high performance expectation, the practices of holding high performance expectation recorded the highest mean score $(M=3.24, S D=0.54)$. This implied that tutors perceived that their principals frequently exercised the leadership practice of holding high performance expectations in the studied colleges. The leadership practice of holding high performance expectations involves actions such as: 'insisting on best performance from tutors; demonstrating to tutors that there are higher performance levels expected of them as professionals; and not settling for second best in tutor performance' (Jantzi and Leithwood, 1996).Principals who exercise these leadership actions are mostly likely to bring the best out of their tutors.

However, the results also showed that tutors viewed their principals to practice weaker transformational leadership styles such as providing individual support and intellectual stimulation. While the practice of 'providing individual support' involves actions such as: 'supporting tutor professional training and development, being considerate to tutor views,their needs and concerns, and providing the necessary resources to support tutor task-accomplishment', Leithwood and Jantzi (1996) indicate that principals who exercise these practices motivate their teachers and build in them the competence and confidence needed for accomplishing their task as leaders of teaching and learning. Recent research studies in this area equally found significant lack of tutor support in this area (see, Osei and Adu, 2016; Odoom et al., 2016; Boadu and Acquah, 2013). For instance, Osei and Adu (2016) discovered that tutors of the studied colleges faced challenges ranging from the absence of finance (to support tutor continuous professional development) to the absence of policy to guide staff support and academic developments (p.311). 
In consequence, this study offers to principals of the studied colleges, an understanding of what their tutors make of their transformational leadership practices and their potential impact on them. The perceptions principals have about their own leadership practices and their influence on tutors' performance may not be co-terminus with those of tutors. Where this state of affair exists, it could breach the sort of principal-tutor productive relationships that support collaborative efforts in response to college goals. Thus, this study offers to principals the opportunity to re-evaluate their leadership relationships with tutors in ways that enhance tutor performance. As Jantzi and Leithwood (1996) put it, principals can positively influence their teachers' performance when they carefully and diligently perform their leadership task and are seen by teachers to do so. However, to what extent do demographic factors account for variations in tutors' perceptions of their principals' transformational leadership practices?

\subsection{Tutor Gender and Perceptions of Leadership}

The results of the gender distribution of the studied fifteen colleges indicated that out of the studied population of 434 tutors, $318(73.2 \%)$ were males and116 (26.7\%) females. This implied that more male than female tutors participated in the study.This result was unsurprising because Dankwa (2013) also found similar results in her study of 252 tutors in the same colleges of education in Ghana. While 156 tutors were male participants, 96 were female tutors. These findings mirror the nationwide statistics of tutor gender ratio in the colleges of education in the country. Here, out of the total of about 1,736 tutors in the 45 public colleges of education, 1,326 were male and 410 females (National Council for Tertiary Education, 'Summary of Basic Statistics on the Colleges of Education', 2017). But does gender influence the way tutors perceive their principals' transformational leadership practices?

In response to the above question, findings from different studies present varied results. For instance, while Lee and colleagues' (1993) study of high school teachers in America indicate that female teachers perceived more positively the leadership practices of their principals than their male counterparts, Jantzi and Leithwood's (1996) study of elementary and secondary school teachers in British Columbia found no statistically significant differences between them. Similarly, findings from Helm's (2012) study of elementary and high school teachers in North Carolina also indicated the lack of statistically significant differences in male and female teacher perceptions of their principals' leadership practices. None of the previous studies conducted in the said colleges examined the impact of gender on tutor perceptions.

Consistent with findings of Jantzi and Leithwood (1996) and Helm's (2012) studies, this current study equally found no statistically significant differences in male and female tutors' perceptions of leadership. This implied that both male and female tutors shared common views about their principals' transformational leadership practices. As Cohen and colleagues (2016) indicated, expressing such shared perceptions imply that the implementation of a transformational leadership policy following these practices is likely to produce common effects on male and female tutors in the said colleges.

\subsection{Tutors' Academic Qualification and Perceptions of Leadership}

The descriptive results of tutor academic qualifications in the studied colleges showed that, while 3 tutors (0.7\%) were diploma holders, 29 (6.7\%) had first degrees. However, a considerable number of 399 (91.9\%) tutors obtained master's degrees and3 tutors (0.7\%) obtained PhDs. Master's degreestill remains the minimum level of qualification for teaching in these colleges. Thus,about $92 \%$ of tutors in the studied colleges met the minimum level of qualification for teaching in these colleges.This distribution reflects the nationwide statistics where $82.3 \%$ of the the total of 1,736 tutors met the minimum qualification for teaching in the public colleges of education in Ghana (National Council for Tertiary Education, 'Summary of Basic Statistics on the Colleges of Education', 2017).To what extent, however, do tutors' academic qualificationsaccount for variations in their perceptions of the transformational leadership practices of their principals?

Findings from research studies show that the knowledge and skills teachers acquire through academic learning, professional training and continuous professional development enhance their professional expertise and builds their confidence as leaders in teaching learning (Bredeson and Johannsson, 2000; Borko, 2004; Bell and Bolam, 2010).Some of these studies indicate that the higher the qualification of teachers, the more competent and confident teachers are as instructional leaders, and the less dependent they may be on principals to be successful. So, understanding the relationship between tutors' qualifications and their perceptions of their principals' transformational leadership was considered vital to this study. However, very few studies explored the relationship between these two variables in the university colleges of education in Ghana.

However, results of other studies in the area present a varied picture. Bigger staff's (2012) study of 179 elementary school teachers in Kentucky in North America indicates that teachers with bachelor's degrees rated their principals' leadership practices higher than teachers with Rank 1 qualification. Unlike Bigger staff's (2012), results of this current study found statistically no significant differences in tutors' perceptions of leadership following their academic qualifications. The lack of perceptual differences between the qualified and nonqualified tutors in the studied colleges was a surprising outcome if one goes by the understanding that highly qualified teachers are likely to be less dependent on their principals. This lack of statistically significant differences is also indicative of tutors' shared perceptions of their principals' leadership in spite of differences in their level of academic qualifications. Yet, teachers' years of experience in the field is also perceived to be a significant predictor of their performance.

\subsection{Tutor Years of Experience and Perceptions of Leadership}

From the descriptive results of the studied university colleges of education, while the minimum years of experience was 1 , the maximum was 35, with an average of 9 years. The descriptive results show that about $64 \%$ of 434 tutors had between 1 to 10 years of experience as tutors.This is significant because studies show that teachers with 
between 1-20 years of experience tend to be experts in their fields of endeavour and exhibit higher performance efficacies than novice teachers (Tschannen-Moran and Hoy, 2001; Wolters and Daugherty, 2007; Klassen and Chiu, 2010). In this way, if teachers' years of experience is a significant predictor of their performance, then doesit also influence the way they perceive their principal's leadership practices?

Results of the analysis in this study found statistically no significant differences between tutors' years of experience and their perceptions of leadership. In contrasting this finding with results of previous studies, one finds a mixed picture. For instance, consistent with the results of this study, Jantzi and Leithwood's (1996) study of 432 elementary and secondary school teachers in British Columbia found that teachers' years of experience did not account for the variations in their perceptions of leadership. Additionally, Biggerstaff's (2012) study of elementary school teachers' perceptions in Kentucky equally found statistically no significant differences between the two variables. However, the studies conducted by Walker and Slear (2011) and Helm (2012) present a different picture.

In Walker and Slear's (2011), significant variations were found in the perceptions of new teachers (0-3 years), experienced (4-7 years) and more experienced teachers (8-14).Novice teachers depended more on their principals' leadership practices than their experienced counterparts. This led Walker and Slear (2011) to conclude that experienced teachers become experts in their field, and thus, need less of certain leadership models of their principals than less experienced teachers. In Helm's (2012) study, results also indicated statistically significant differences, especially, teachers with between 11-15 years of experience and 25 or more years of experience. These teachers relied less on their principals' leadership practices to be effective.

While this current study found no statistically significant differences between tutors' years of experience and variations in their perceptions of leadership, could this be the result of their average experience of 9 years? Many empirical research studies consistently indicate that experienced teachers with between 8 to 20 years are always competent in their teaching endeavour and need less of principals' leadership guidance (Wolters and Daugherty, 2007; Klassen and Chiu, 2010' Walker and Slear, 2011).Yet, the lack of statistically significant differences in tutors 'perceptions of leadership following their years of experience suggests that tutors share common views about their principals' transformational leadership practices in the studied colleges. These common views might be the consequence of the implementation of the T-Tel (Transforming Teacher Education and Learning) program in these colleges over the past four years (see, T-TEL, 2015). In this way, the implementation of a transformational leadership policy in the studied colleges in response to colleges goals is likely to produce the same effects on tutors regardless of their years of experience.

\section{Conclusion and Implications}

This study specifically focused on examining tutors' views on the extent to which they considered the leadership practices of their college principals to be transformational. In examining these perceptions, the study also investigated the extent to which demographic factors such as gender, academic qualification and years of experience may account for variations in tutors' perceptions of leadership. The descriptive results indicated that tutors of the studied university colleges considered that their principals exercised transformational leadership practices such as: provides vision, models behaviour, fosters commitment, and hold high performance expectations. Tutors also viewed that their principals exercised less of the following transformational leadership strategies:providing individual support and intellectual stimulations. While these two leadership strategies have the potential to positively impact on tutor performance, principals of the studied colleges might need to review their leadership practices to ensure their effective application as means to enhancing tutor performance.

Furthermore, the study also found that tutors' demographic factors such as gender, academic qualification and years of experience did not account for any statistically significant differences in their perceptions of the transformational leadership practices of their principals. These results implied that tutors of the studied university colleges shared common perceptions in respect of their principals' transformational leadership practices albeit the differences in their gender, qualifications and experience. This implies that principals who seek to exercise these transformational leadership strategies as effective means to enhancing tutor performances in response to college goals are likely to produce common effects on them.

\section{Implications of the Study}

First of all, the perceptions of principals about their own leadership practices and how these practices impact on tutors' performance and contribute to achieving college goals may not always be coterminous with tutors' perceptions. Where such dichotomies exist, they could create the sort of principal-tutor disengagements which impede the development of productive relationships that support collaborative efforts in response to college goals. Exercising one's leadership in response to college goals and being seen to do so by tutors provides the most powerful strategy for positively influencing tutors' performance (Jantzi and Leithwood, 1996). This study therefore offers to principals of the University Colleges of Education in Ghana, tutors' views about their leadership. Considering the positive impact transformational leadership has on schools, the results of this study can helpfosterbetter principal-tutor relationship in response to college goals through the conscious application of these leadership strategies in their colleges.

Secondly, the study demonstrated that tutors viewed their principals to exercise transformational leadership practices such as: providing vision, fostering commitment, modelling best behaviour nd holding high performance expectations. However, tutors rated their principals to be less effective in their leadership practices of providing individual support and intellectual stimulation. Yet, studies in the area show that these two transformational leadership strategies are significant predictors of principal leadership effectiveness in schools. This is because not only do these two factors focus on the principal's respect for tutors, care for their personal needs and professional development, they also relate to 
the extent to which principals are able to challenge tutors to embrace modern and innovative techniques of teaching and learning as the effective means to promoting critical thinking and problem solving skills among student-teachers.

Last but not least, the lack of statistically significant differences in tutors' perceptions following their gender, academic qualification and years of experience suggest that principals who seek to exercise the aforementioned transformational leadership practices are likely to produce similar effects on their tutors despite the differences in their demographic factors.

\section{Limitations and Recommendations}

This study was quantitative in nature. It relied on the use of questionnaire to elicit tutors' views on the leadership practices of their college principals. Although questionnaires are viewed to be reliable for eliciting requisite information from respondents for data analysis, they are nonetheless known for imposing a structure on answers and shape the nature of respondents' responses (Denscombe, 2014: 181). So, complementing results of the quantitative analyses with results from interviews or focus group discussions is recommended because interviews and focus groups allow respondents to express other opinions beyond the researcher's structured questions. The qualitative findings may could also provide explanatory power to the results of the quantitative study.

Furthermore, the analysis of data in this study only represented the subjective responses of tutors. These responses may not necessarily represent principals' views on their own leadership practices and their impact on colleges. Consequently, a study that also includes principals' views about their won leadership practices is deemed significant. The corroboration of tutors' views with those of their principals may offer a holistic picture about principal leadership perceptions in the university colleges of education in Ghana.

Additionally, in measuring tutors' perceptions of their principals' transformational leadership, the study only usedJantzi and Leithwood's (1996) six factors of the principals' leadership questionnaire (PLQ).Even though research studies in the area show that the instrument is valid and reliable for measuring such perceptions, it is however possible that principals of the studied colleges also exercise other forms of transformational leadership practices which are not captured by the six factors of the PLQ. In this way, a follow-up study that uses qualitative methods may contribute to uncovering other forms of leadership practices in these colleges.

\section{References}

i. Allix, N, M. (2000) Transformational Leadership: Democratic or Despotic? Educational Management and Administration, 28(1), 7-20.

ii. Antonakis, J., Avolio, B. J., and Sivasubramaniam, N. (2003). Context and leadership: An Examination of the NineFactor Full-Range Leadership Theory Using the Multifactor Leadership Questionnaire. The Leadership Quarterly, 14(3), 261-295

iii. Artiles, D. (2013). The Rise of American Urbanized Suburban High Schools: Teachers' Perceptions of Leadership. (Ed.D., Fordham University). ProQuest Dissertations and Theses, Retrieved from https://search.proquest.com/docview/1431455832?accountid=12753 (02/03/2018)

iv. Avolio, B, J., Bass, M. and Jung, D, I. (1999) Re-Examining the Components of Transformational and Transactional Leadership Using the Multifactor Leadership Questionnaire the. Journal of Occupational and Organisational, 72, 441-462.

v. Avolio, B.J., \& Bass, B.M. (2004). Multifactor leadership questionnaire, manual and sample set (3rd ed.). Menlo Park, CA; Mind Garden Inc.

vi. Avalos, B. (2011) Teacher Professional Development in Teaching and Teacher Education over Ten Years. Journal of Teaching and Teacher Education, 27, 10-20.

vii. Avci, 0. (2012). The Relationship Between Transformational Leadership Behaviours of Faculty Supervisors and Self-Efficacies of Graduate Assistants. (Ed.D., Northern Illinois University). Pro Quest Dissertations and Theses, Retrieved from https://search.proquest.com/docview/1024732976?accountid=12753(02/02/2018).

viii. $\quad$ Bass, B.M. (1985). Leadership and Performance Beyond Expectations. New York: The Free Press.

ix. $\quad$ Bass, B. M. (1990). Leader March: A Handbook of Leadership. New York: The Free Press.

X. Bass, B. M. \& Avolio, B. J. (1990). The Implications of transactional and Transformational leadership for Individual, team, and Organizational development. Research in Organizational Change and Development, 4, 231272.

xi. Bass, B.M. \& Avolio, B.J., 1993, 'Transformational leadership: A response to cri ques', in Chemers, M, M. \& Ayman, R. (eds.), Leadership Theory and Research: Perspectives and Directions: Academic Press, New York. Pp.49-80

xii. Bass, B. M. (1998). Transformational Leadership: Industrial, Military, and Educational Impact. Mahwah, NJ: Erlbaum.

xiii. Bass, B.M. \& Avolio, B.J. (1999). Two Decades of Research and Development in Transformational Leadership. European Journal of Work and Organizational Psychology, 8(1), 9-32.

xiv. Bass, B.M., Avolio, B.J., Jung, D.I., \&Bergson, Y., (2003). Predicting Unit Performance by Assessing Transformational and Transactional Leadership. Journal of Applied Psychology, 88(2), 207-218.

xv. Baumeister, R. F., \& Leary, M. R. (1997). Writing Narrative Literature Reviews. Reviewof General Psychology, 1(3), $311-320$. 
xvi. Bell, L. and Bolam, R. (2010) Chapter 6: Teacher Professionalism and Continuing Professional Development: Contested Concepts and Their Implication for School Leaders. In: Bush, T., Bell, L. \& Bolam, R., ed., The Principles of Educational Leadership and Management. London: SAGE. pp. 89-111.

xvii. Bennardo, D. P. (2007). The Transformational Leadership Characteristics of The Building Principal as A Predictor of High School Teacher Efficacy. (Ed.D., St. John's University (New York), School of Education and Human Services). ProQuest Dissertations and Theses, Retrieved from https://search.proquest.com/docview/1896629610?accountid=12753

xviii. Borko, H. (2004) Professional Development and Teacher Learning: Mapping the Terrain. Educational Research, 33(8), 3-15.

xix. Bredeson, P, V. and Johansson, O. (2000) The School Principal's Role in Teacher Professional Development. Journal of In-Service Education, 26(2), 385-401.

xx. Dankwa, J, A. (2013) Transformational Leadership in Colleges of Education in Ghana: Teachers' Perspectives. Journal of Education and Practice, 4(16), 187-195.

xxi. Day, C., Gu, Q. and Sammons, P. (2016) The Impact of Leadership on Student Outcomes: How Successful Leaders Use Transformational and Instructional Strategies to Make a Difference. Educational Administration Quarterly, 52(2), 221-258.

xxii. Fitzgerald, T. T. (2015). A Study Exploring Transformational Leadership and Its Impact On Teacher Efficacy, Teacher Trust, And Change Readiness. (Ed.D., Concordia University Chicago). ProQuest Dissertations and Theses, Retrieved from https://search.proquest.com/docview/1705816534?accountid=12753 (02/03/2018).

xxiii. Garet, M, S., Porter, A, C., DeSimone, L., Birman, B, F. and Suk Yoon, K. (2001) What Makes Professional Development Effective? Results from a National Sample of teachers. American Educational Research Journal, 38(4), 915-945

xxiv. Hallinger, P. (2003) Leading Educational Change: Reflections on the Practice of Instructional and Transformational Leadership. Cambridge Journal of Education, 33(3), 329-351.

xxv. Hallinger, P and Heck, R, H. (2010) Leadership for Learning: Does Collaborative Leadership Make a Difference in School Improvement? Educational Management Administration and Leadership, 38(6), 654-678.

xxvi. Hartley, D. (2004) Management, Leadership and the Emotional Order of the School, Journal of Education Policy, $19(5), 583-594$.

xxvii. Hauserman, C, P. and Stick, S. (2013) The Leadership Teachers Want from Principals: Transformational. Canadian Journal of Education, 36(3), 184-203.

xxviii. Hoxha, L. and Hyseni-Duraku, Z. (2017) The Relationship Between Educational Leadership and Teachers' selfefficacy. The European Journal of Social and Behavioural Science, 20, 2301-2218.

xxix. Le Fevre, D, M. and Robinson, V, M. (2015) The Interpersonal Challenges of Instructional Leadership: Principal Effectiveness in Conversations About Performance Issues. Educational Administration Quarterly, 51(1), 58-91.

$x x x . \quad$ Leithwood, K. (1992). The move toward transformational leadership. Educational Leadership, 49(5), 8-12.

xxxi. Leithwood, K. (1994). Leadership for school restructuring. Educational Administration Quarterly, 30(4), 498518.

xxxii. Leithwood, K. and Beatty, B. (2008) Leading with Teacher Emotions in Mind. United States of America: Corwin Press: A Sage Company

xxxiii. Leithwood, K., \& Jantzi, D. (2000). The Effects of Transformational Leadership on Organizational Conditions and Student Engagement. Journal of Educational Administration, 38(2), 112- 129.

xxxiv. Leithwood, K., \& Jantzi, D. (2005). A Review of Transformation School Leadership Research $1996-2005$. Leadership and Policy in Schools, 4, 177-199.

xxxv. Leithwood, K., Jantzi, D. \& Steinbach, R., (1999). Changing leadership for changing times. Buckingham, Philadelphia: Open University Press.

xxxvi. Leithwood, K., Day, C., Sammons, P., Harris, A. and Hopkins, D. (2006) Seven Strong Claims about Successful School Leaders. London: DfEs.

xxxvii. Leithwood, K., Anderson, E. S., Mascall, B. \& Strauss, T. (2010) Chapter 2: School Leaders' Influence on Student Learning: The Four Paths. In: Bush, T., Bell, L. \& Bolam, R., ed., The Principles of Educational Leadership and Management. London: SAGE. pp. 13-30.

xxxviii. Marks, H, M. and Printy, S, M. (2003) Principal Leadership and School Performance: An Integration ofb Transformational and Instructional leadership. Educational Administration Quarterly, 39(3), 370-397.

xxxix. Middlewood, D. (2010) Chapter 8: Managing People and Performance. In: Bush, T., Bell, L. \& Bolam, R., ed., The Principles of Educational Leadership and Management. London: SAGE. 132-150.

xl. Nelson, A. (2012). The Relationship Between Middle School Teachers' Perceptions of Principals' Transformational Leadership Practices, Teachers' Sense of Efficacy And Student Achievement. (Doctoral Dissertation, University of Southern Mississippi, 2012. UMI No. 3530736).

xli. Nelson, E. (2013). The Upgrading of the Teacher Training Colleges to Colleges of Education: Issues and Prospects. African Journal of Teacher Education, 3(2), 1-14.

xlii. Odoom, D., Opoku, E. and Ayipah, D. N. (2016). Staff Development Needs at the Colleges of Education in Ghana: Evidence from Agogo College. International Journal of Innovative Research and Development, 5(1), 127-137.

xliii. Osei, A. A., And Adu, K. O. (2016). Transitional Challenges Facing Staff Development in Selected Colleges of Education in Ghana. International Journal of Research in Economics and Social Science, 6(4), 301-315. 
xliv. $\quad$ Rhodes, C. and Brundrett, M. (2010) Chapter 9: Leadership for Learning. In: Bush, T., Bell, L. \& Bolam, R., ed., The Principles of Educational Leadership and Management. London: SAGE. Pp. 153-175.

xlv. Ross, J. and Gray, P. (2006) Transformational leadership and Teacher Commitment to Organisational Values: The Mediating Effects of Collective Teacher Efficacy. School Effectiveness and School Improvement, 2, $179-199$.

xlvi. Rowold, J. (2005) Multifactor Leadership Questionnaire: Psychometric Properties of the German Translation. Mind Garden Inc.

xlvii. Schriesheim, C, A., Wu, J, B. and Scandura, T, A. (2009) A Meso Measure? Examination of the Level of Analysis of the Multifactor Leadership Questionnaire. The Leadership Quarterly, 20, 604-616.

xlviii. Sharma. R. and Singh, S. Transformational Leadership Styles and Efficacy among Teaching Professionals. International Journal of Indian Psychology, 4(2), 140-147.

xlix. Shatzer, R, H., Caldarella, p., Hallam, P. and Brown, B, L. (2013) Comparing the Effects of Instructional and Transformational Leadership on Student Achievement: Implications for Practice. Educational Management Administration and Leadership, 42(4), 445-459.

l. Stewart, J. (2006) Transformational Leadership: An Evolving Concept Examined through the Works of Burns, Bass, Avolio, and Leithwood. Canadian Journal of Administration and Policy, 54, 1'28.

li. Urick, A. and Bowers, A. (2014) What are the Different Types of Principals Across the United States? A Latent Class Analysis of Principal Perceptions of Leadership. Educational Administration Quarterly, 50(1), 96-134.

lii. Walker, J. and Slear, S. (2011) The Impact of Principal Leadership Behaviour on the Efficacy of New and Experienced School Teachers. NASSP Bulletin, 95(1), 46-64.

liii. Yukl, G. (1999). An Evaluation of Conceptual Weaknesses in Transformational and Charismatic Leadership Theories. Leadership Quarterly, 10, 285-305 